\title{
Las formas y los contextos de útiles pulimentados. Análisis de piedras pulidas de la Colección Robert Junghanns del Instituto de cultura puertorriqueña
}

\section{The forms and contexts of polished tools. Analysis of polished stones from the Robert Junghanns Collection of the institute of Puerto Rican culture}

\author{
Nichole L. Bodin Cruz \\ https://orcid.org/0000-0002-0343-343X \\ Centro de Estudios Avanzados de Puerto Rico y el Caribe \\ enelle.bodin@gmail.com
}

\section{RESUMEN}

Esta investigación fue motivada ante la necesidad de identificar la gran variabilidad estilística de artefactos líticos pulidos encontrados dentro de la Colección Arqueológica de Robert Junghanns del Instituto de Cultura Puertorriqueña. La manufactura de artefactos líticos pulidos contienen un significado económico que permite subestimar la homogeneidad de la estrategia de subsistencia básica en diferentes grupos en la historia, un papel importante con relación a las necesidades de sobrevivencia. Este análisis tipológico-funcional de los instrumentos líticos encontrados en la Colección intenta presentar, clasificar y describir una serie de implementos líticos (sin procedencia), estableciendo así 7 clases de diferentes artefactos de acuerdo al tipo, materia prima, técnicas de manufactura empleadas y morfología que poseen.

Palabras clave: Industria lítica del Caribe; Colección Robert Junghanns; morfología; metodología; hachas petaloides. 


\section{ABSTRACT}

This research was motivated by the need to identify the great stylistic variability of polished stones within the Robert Junghanns Archaeological Collection of the Institute of Puerto Rican Culture. The manufacture of lithic polished materials have an economic significance that allows the underestimation of the homogeneity for the basic subsistence strategy of different groups in history, an important role in relation to various survival needs. This typological-functional analysis of the lithic instruments found in the Collection tries to present, classify and describe a series of lithic implements (from an unknown origin) and establishing 7 classes of different artifacts according to the type, raw material, manufacturing techniques used and the morphology they possess.

Keywords: Caribbean Lithic Industry; Robert Junghanns Collection; morphology; methodology; petaloid celts.

Recibido: 10/08/2018 - AcePtAdo: 15/08/2020 - Publicado: 10/05/2021

\section{INTRODUCCIÓN}

El Caribe ha surgido de las sombras arqueológicas como una región crítica que responde a una serie de preguntas relacionadas con la dispersión de la población humana, las adaptaciones sociales de las islas Neo-tropicales, la subsistencia marítima, las redes de interacción de las islas y el aumento de la complejidad social. Desde principios de los años treinta, los estudios tipográficos cronológicos en la arqueología caribeña se utilizaron para describir el desarrollo cultural en el Caribe sobre la base conceptual de la cerámica, representando solo una parte de la cultura material de las comunidades del Caribe. Pero afortunadamente, el número de estudios orientados a establecer las secuencias operativas observadas en la producción lítica en el Caribe está evolucionando desde una perspectiva tecnológica emancipada de tipologías importadas de otros contextos (Rodríguez, 2007, p. 57). En el contexto de las sociedades, la identificación de la procedencia de la materia prima ha demostrado ser útil para conocer la forma en que el hombre interactúa con su entorno y otras comunidades humanas. Por lo tanto, la relación entre el paisaje y su organización social para la producción de herramientas de lítica requieren una consideración ante las cuestiones que se encuentran dentro de la investigación arqueológica de Las Antillas. La producción de los artefactos hechos de rocas es la industria tecnológica de más larga vida en la historia de la humanidad (Rodríguez, 2010, p. 27).

Los desechos de talla lítica son los materiales más omnipresentes y abundantes de todos los artefactos, y su análisis es fundamental para la rama de la arqueología (Clitford, 2000, p. 619). El problema que tiene el estudio y la clasificación de las in- 
dustrias de piedra es su gran heterogeneidad, ya que existen diferentes conceptos, términos y formas de clasificar entre diferentes autores. En el caso de la Arqueología del Caribe, un conocimiento más teórico que un estudio práctico sería lo idóneo (en la relación del desarrollo de actividades complementarias) para entender estas variedades y sus función. Hasta la fecha, no se ha desarrollado una metodología clara para tratar con conjuntos líticos precolombinos en las islas caribeñas. (Pantel,1988, p. 30).

Debido a que los cambios en la cultura material responden a la manifestación de modificaciones étnicas, migraciones, invasiones o a las consecuencias de una difusión de objetos y/o ideas, el hallazgo de núcleos de piedras representan las características necesarias para ser considerados como materia prima de futuras herramientas líticas. Éstos procesos de interpretación usualmente pueden diferir en algunos aspectos relacionados con la función de la metodología, ofreciendo a su vez explicaciones sobre la realidad prehistórica y la base de conocimientos científicos. La perspectiva 'ceramocentrista' incrustada en el espacio de tiempo que Irving Rouse postuló en el Caribe ha resultado en la imposición de una condición relacionada a otros tipos de materiales a través de la construcción de una línea de vida histórica, de manera similar a la impuesta sobre los pueblos "arcaicos" (Rodríguez, 2010, p. 5). Pero aún así, la labor de Rouse tiene una importante influencia en arqueólogos como Ricardo Alegría, quien establece para Puerto Rico los primeros asentamientos pre-agrícolas y materiales de contacto con Venezuela y otros puntos del área. (Veloz, 1979, p. 130). El análisis tecnológico lítico combina varios aspectos que ayudan a entender mejor aún el conocimiento de parámetros tales como la mecánica de rotura, las técnicas de producción, la reproducción experimental y su uso (así como otros aspectos) para así entender la biografía del objeto lítico de adquisición de la materia prima, la producción de objetos líticos y su análisis (Frick, 2014, p. 130).

No obstante, los estudios arqueológicos deberían de evitar las visiones puramente tipológicas, ya que en la extracción de un ensamblaje de artefactos líticos se tiende a ofrecer un solo nombre a una pieza lítica. Por eso la mayoría de las tipologías han sido, y siguen siendo, utilizadas para la clasificación de materiales enlascados en las colecciones del Caribe, basadas en taxonomías continentales que permiten una interpretación mínima para el estudio de artefactos líticos producidos en un área como las Indias Occidentales (Rodríguez, 2006, p. 5).

A través de éste estudio de tipologías y sus aspectos tecnológicos, se pudo evaluar el cambio y/o continuidad de los conjuntos de artefactos líticos en una perspectiva diacrónica. El uso de productos líticos como ilustración de las relaciones sociales de producción mediante la promulgación de tradiciones dentro del enfoque actual logran analizar los productos finales y sus contextos de recuperación, así como materias primas no alteradas, preformas descartadas y todo el material pro- 
ducido durante su fabricación (Rodríguez, 2010, p. 29). Es tanto así que diferentes estudios arqueológicos han encontrado evidencias de la Era Arcaica (semi-nómadas, pre-agrícolas/pre-cerámicas) en la mayoría de las islas del Caribe que han indicado movimientos migratorios en la región de América del Sur, América Central y tal vez América del Norte. La continuidad de éstas tradiciones tecnológicas, en especial la producción lítica entre las diferentes manifestaciones culturales definidas (Rodríguez, 2007, p. 24), y en comparación con la tradición alfarera (Rouse 1992), fue cambiando a través del tiempo.

Los procesos de producción lítica comienzan con la adquisición de materias primas y sus propiedades que las hacen funcionales de acuerdo al material para su transformación en herramientas (Rodríguez, 2010, p. 30). Un aspecto muy importante es la direccionalidad de la manufactura de la herramienta de piedra, refiriéndose a que el tamaño de la masa puede disminuir a través de la continua reducción/ uso/descarte (Rodríguez, 2006, p. 4). En lo particular, los materiales de pequeño tamaño han sido irregularmente recuperados y la recuperación del tamizado del suelo resulta usualmente incompleta durante el proceso de excavación (Clitford, 2000 , p. 624). La ubicación geográfica o el período de tiempo puede argumentar de qué manera los materiales líticos reflejan el conocimiento de la explotación del paisaje y de la organización social necesaria para comenzar y preparar la explotación de diferentes productos. La ausencia del estado final de la pieza abandonada es lo único que los arqueólogos tienen para el estudio de la reducción lítica (Morales, 2013, p. 543). La mayoría de las tipologías han sido, y siguen siendo, utilizadas para la clasificación de materiales enlascados en las colecciones del Caribe, basadas en taxonomías continentales que permiten una interpretación mínima para el estudio de artefactos líticos producidos en un área como las Indias Occidentales (Rodríguez, 2006, p. 5).

Uno de los principales problemas al analizar las piezas líticas fue distinguir cuáles eran pulidas (con alguna modificación intencional antrópica) y cuáles no. La identificación de tipos de herramientas como cortadores, raspadores, cuchillas y grupos similares tiene limitaciones inherentes para explicar su utilidad a través de los registros arqueológicos en complejos precolombinos (Pantel,1988, p. 28). La mayoría de las publicaciones sobre la arqueología de las Indias Occidentales han utilizado las taxonomías ya desarrolladas y encajan los artefactos en la categoría preestablecida apropiada, como la hoja, el cortador, la lasca y otros similares (Pantel, 1988, p. 27). La industria lítica pulimentada se manifiesta a través de la técnica de rozamiento con la materia prima para modificar un elemento abrasivo (usualmente de piedras areniscas y otras rocas de grano grueso), logrando un desgaste en la materia prima. Esto provoca una disminución del volumen de la pieza y una aparición de superficies lisas y homogéneas que reducen la materia prima hasta la forma deseada mediante la percusión. 
La carencia de los procesos de identificación de materias primas es uno de los temas abordados por los estudios líticos y uno de los más controversia en cuanto a la carencia de consenso de identificación. Los artefactos elaborados por los grupos indígenas del Caribe fueron desarrollados con técnicas sofisticadas que permitieron la producción de herramientas utilitarias, además de carácter ritual (Rodríguez, 2012, p. 1). Un análisis más detallado de los materiales producidos con piedras proveería importante información para delinear los procesos de interacción y los contactos registrados entre las diversas comunidades indígenas del Caribe (Rodríguez, 2012, p. 1).

Los hallazgos de herramientas de piedra demuestran el progreso cultural que las sociedades lograron a través de su ínter-relación con otras sociedades y su medio ambiente. El análisis de los artefactos líticos y la tecnología relacionada con el período cerámico ha sido, y continúa siendo, un campo poco estudiado dentro la Arqueología del Caribe (Knippenberg, 2006, p. 94).

\section{COLECCIÓN JUNGHANNS}

Robert Ludwig Junghanns nace el 1 de julio de 1875 en la ciudad de Poughkeepsie, en el estado de Nueva York y muere en Hato Rey, Puerto Rico el 21 de septiembre de 1947. Al llegar a Puerto Rico se dedicó al comercio, a estudiar y a preservar materiales relacionados con la cultura puertorriqueña. Como coleccionista, tomó un papel importante en la búsqueda y conservación historia de objetos indígenas que ahora son recursos importantes en las Colecciones del Instituto de Cultura Puertorriqueña y el Archivo General de Puerto Rico. En 1959, el Instituto de Cultura Puertorriqueña (ICP) adquirió la diversa Colección Junghanns, el cual poseía en aquel entonces, una gran variedad de documentos, libros, antigüedades, manuscritos, cintas magnéticas, etc. Debido a su diversa documentación, el ICP depositó la Colección en diferentes unidades programáticas. Los manuscritos y la documentación impresa fueron transferidas al Archivo General de Puerto Rico, mientras que los artefactos fueron depositados en programas de Arqueología y a Parques y Museos. La documentación de la Colección tiene dos fuentes principales: las agencias de gobierno en Puerto Rico desde el Siglo XIX y principios del Siglo XX y otras de colecciones privadas. Esta serie contiene una acumulación de documentación de diferentes fuentes, con manuscritos importantes rescatados por el coleccionista a través de entrevistas que relatan algunas tradiciones orales puertorriqueñas, canciones, historias y más. Pero, por razones de preservación y seguridad, las postales puertorriqueñas y paisajes eróticos de tiempo fueron trasladados al Archivo Fotográfico. En 1999, la colección es organizada como una fuente original de los documentos identificados que cubre el período de la colonia española y las primeras décadas de la administración estadounidense. La colección original se rompió cuando Junghanns vendió su colección de libros por un dólar en la Universidad de Puerto Rico en 1930. Actualmente, estos 
libros son parte del patrimonio de Rare Books Collection de la Colección Puertorriqueña de la Biblioteca José M. Lázaro de la Universidad de Puerto Rico en Río Piedras. Después de la muerte de Robert L. Junghanns, su casa fue vandalizada y algunos de los artefactos de la colección desaparecieron. Actualmente, la colección de artefactos arqueológicos y artesanías se pueden encontrar en la bóveda del Instituto de Cultura Puertorriqueña. Estas series contienen una acumulación de documentos de diferentes fuentes y manuscritos importantes rescatados por el coleccionista a través de sus entrevistas. Actualmente, el Instituto de Cultura Puertorriqueña está en proceso de convertirse en un hotel ante un acuerdo firmado en 2016 por el ex-gobernador Alejandro García Padilla, por lo que pronto ésta y otras colecciones pudiesen quedar en el olvido.

\section{METODOLOGÍA DE ESTUDIO}

El trabajo lítico es clasificado de acuerdo a las técnicas de manufactura y su proceso comprende de dos factores; los cuales se pueden describir a través del ordenamiento lógico y sistemático de la técnica aplicada con base en reglas, mecanismos, orden y procedimientos y la técnica de la aplicación con un método específico para lograr un implemento funcional (Peytrequín, 2011, p. 5).

Durante el proceso de análisis, se identificó la hoja como el cuerpo propiamente del artefacto, su extremo distal es el filo y el proximal el talón (Vega, 1975, p. 211). El filo, en vista dorsal, se clasifica como uno rectilíneo y redondeado, con arco rebajado y expandido (Vega,1975, p. 218). En el filo rectilíneo, es clasificado como la relación AB es cero o cercana a cero (Vega, 1975, p. 218). En el redondeado, cuando la altura máxima de $A B$ es mayor que la mitad de la longitud de AC (Vega,1975, p. 218). En arco rebajado, cuando AB es menor a la mitad de la longitud de AC (Vega,1975, p. 218). El filo expandido aparece cuando los lados de la hoja se abren antes de que éste empiece, y su proporción corresponde a la del filo en arco rebajado (Vega,1975, p. 218). El talón, al observarse en vista dorsal, se divide en recto, redondeado y en ángulo (Vega, 1975, p. 218). Ésta es la zona donde se realiza el enmangado por estar en la parte proximal del cuerpo. (Vega:1976, p. 218) (ver figura 01).

Se pudo detectar los cortes longitudinales del bisel y éstos eran simétricos, asimétricos y laterales, pudiendo ser cada uno además convexo, rectilíneo o convexo-rectilíneo (Vega, 1975, p. 218). La sección transversal se clasifica según una base de figuras geométricas a la que se aproximan a una figura circular, elíptica, elíptica recta, semi-elíptica, triangular, cuadrada, rectangular, rectangular curva y trapecial (Vega:1975, p. 218) (figura 02).

La figura elíptica se dividió en 3 grupos, de acuerdo con los índices correspondientes: elíptica 1 con índice normal o mediano, y elíptica 2 con índices delgados y muy delgados y semi-elíptica. Se registraron los datos referentes a la fase del des- 


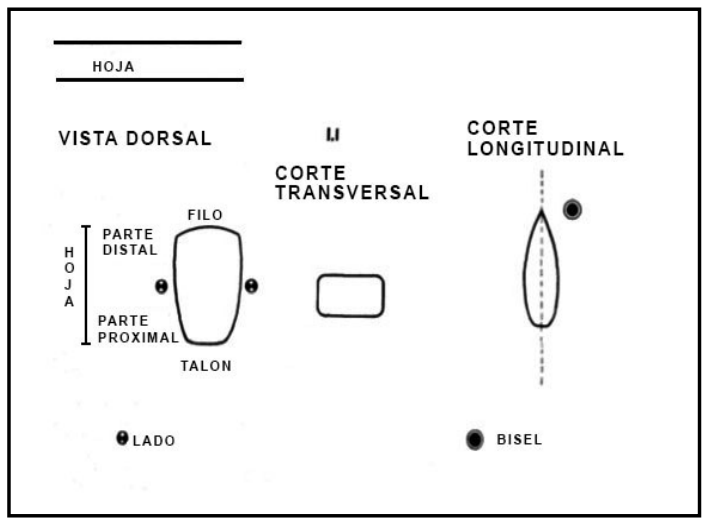

Figura 01. (Vega, 1976, p. 218)

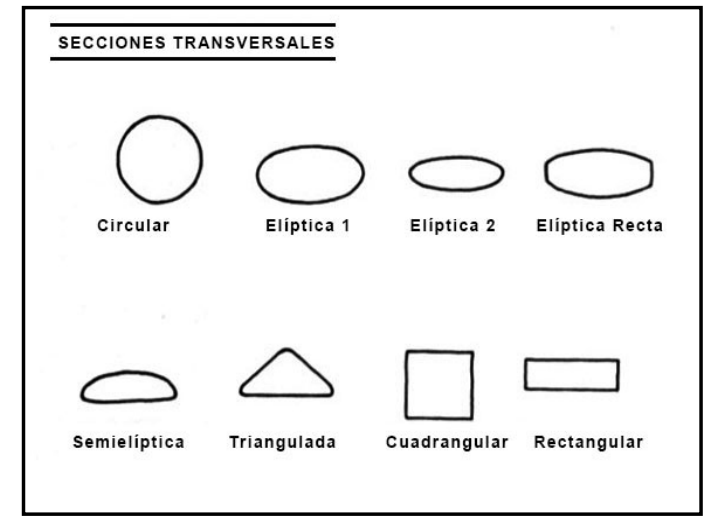

Figura 02. (Vega; 1976, p. 218)

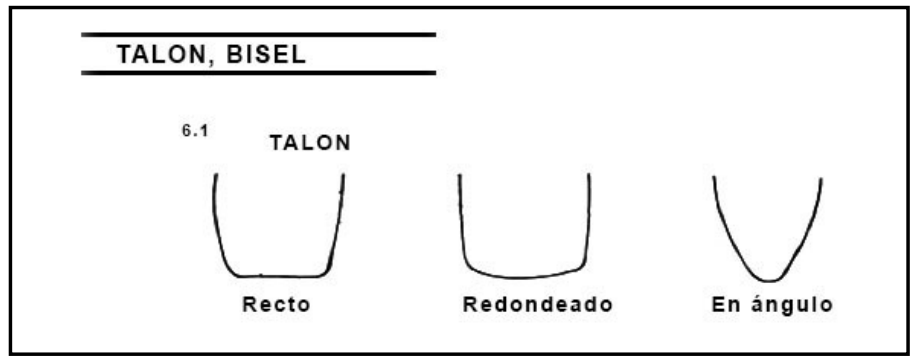

Figura 03. (Vega, 1976, p. 218)

gaste empleada al término de su fabricación: abrasión, pulido o bruñido, indicando si se presentan en forma total o parcial (ver figura 03).

Las variables relacionadas con el estudio que se pretende indagar a través del bisel va más allá de su definición. Éste es sólo reducido a una clasificación entre hachas y azuelas sin ningún análisis detallado. Como el trabajo de la piedra es una tecnología reductora, la medición del grado en que el proceso ha progresado a menudo constituye la base de muchos análisis modernos (Balme, 2006, p. 182). La percusión indirecta ocurre cuando el bloque que se quiere modificar y/o el percutor utiliza otro implemento asegurando la precisión del impacto, sosteniendo la roca con las piernas, o con ayuda de otra persona en el proceso. Además, entre el bloque que se quiere modificar y el percutor, se utiliza otro implemento (e.g. cincel) para asegurar la precisión del impacto (Peytrequín, 2011, p. 6). La presión es un modo de lasqueo que se da al aplicar presión sobre (o contra) la piedra que se quiere modificar hasta obtener pequeñas lascas como piezas de extracción. El desbastado crea distintas superficies activas y éstas permiten que las piezas se utilicen como instrumentos enlasqueados que pueden retocarse con dicha técnica y también transformarse en implementos útiles. 
El desprendimiento de segmentos de una roca (lascas) se difiere básicamente por la percusión de una roca con otra para quebrar y por obtener de ésta trozos más menudos y de fácil manipulación (Peytrequín, 2011, p. 6). La percusión directa a mano sujeta consiste en golpear un bloque de piedra como objeto de la modificación con otro que sirve de yunque sin soltar la roca (Peytrequín, 2011, p. 6). La percusión directa a mano libre modifica una roca por medio de un percutor para obtener lascas y hojas. El percutor puede ser duro (como sílex) o blando (como madera, asta o hueso) $\mathrm{y}$ consiste en golpear un bloque de piedra u objeto de la modificación contra otro que sirve de yunque. Esta acción se realiza sin soltar la roca; sosteniéndola con una o ambas manos (Peytrequín, 2011, p. 6).

La técnica del picado y pulido se aplica mediante golpes (o picoteo) con instrumentos de mayor dureza, sobre el elemento lítico objeto de la transformación. Para la manufactura de artefactos, pueden darse en conjunto el picado y el pulido. La técnica del pulido se logra por el constante rozamiento de un bloque de piedra con algún tipo de abrasivo, desgastando la roca y alterando su superficie para reducir el volumen y obtener así una superficie lisa (Peytrequín, 2011, p. 10). La técnica de la talla consiste en ejercer golpes en los bordes de una piedra para poder así extraer lascas y transformarlas en un objeto con una utilidad en particular o para éste ser transformado en otros artefactos. Esta técnica fue implementada en la producción de petroglifos y otros artefactos, tales como hachas, trigonolitos y aros líticos, entre otros. Con la técnica del picoteo, la piedra pasa por un proceso de reducción para remover la parte de su superficie usando otro implemento lítico y es usualmente acompañada por el proceso de pulimento. Cuando el pulimento es muy intenso, se le llama bruñido, y este es visto generalmente en las hachas petaloides. La arena mezclada con agua es utilizada como agente abrasivo para remover imperfecciones en la superficie del artefacto.

La percusión y el desgaste son las técnicas de fabricación fundamentales, y las herramientas ya terminadas pueden a su vez ser usadas en trabajos a base de las mismas técnicas (Vega, 197, p. 209). La abrasión es la primera fase del desgaste en el cual se da un acabado burdo a la superficie del objeto que se fabrica, usando piedras abrasivas más duras (Vega, 1975, p. 210). La segunda fase del desgaste es el pulido, logrando superficies más lisas mediante la frotación con materiales más suaves (como un trozo de madera dura o una piedra) y usando arena fina y agua (Vega, 1975, p. 210). El bruñido es la última fase del desgaste y se da brillo al objeto con un material blando, como piel o tela y hueso molido (Vega, 1975, p. 210). Con la técnica de la percusión, en sus modalidades de lanzada y apoyada, se obtienen los objetos de piedra tallada, y que con el desgaste se logran los artefactos de piedra pulida, como resultado de un avance técnico (Vega, 1975, p. 210).

La primera clasificación que se realiza con relación a las rocas es la materia prima. Esto implica el uso de una gran variedad de técnicas de manufactura y acabado 
como el desgaste, el vaciado, la perforación (bicónica y/o cilíndrica), la incisión y el pulido. Destacar la variedad de instrumentos utilizados, como son los percutores, cinceles, gubias y pulidores revela la complejidad tecnológica y el grado de especialización contenido en este tipo de herramientas pre-históricas. Durante el proceso de la manufactura de artefactos pueden darse en conjunto la técnica del picado y el pulido. La técnica del pulido se logra por el rozamiento de una piedra con algún tipo de abrasivo, creando un desgaste y alteración en la roca para reducir su volumen y lograr una superficie más lisa (Rodríguez, 2012, p 1). En muchas ocasiones, la pieza es reciclada y vuelve a entrar por un tiempo en la cadena operativa. Por lo tanto, las técnicas de manufactura dependen de las propiedades físicas de la materia prima utilizada. No todos los elementos líticos se comportan de igual manera, por lo que no se usaban para las mismas actividades, entrando en juego aspectos como la estructura, grado de dureza, tipo de fractura y la textura de las piedras.

Las materias primas se deben de clasificar de acuerdo a material de las rocas factor que afecta los procesos de erosión y transporte, por lo que un estudio de bibliografía especializada (con fotografías y dibujos) ayuda a efectuar las oportunas comparaciones analíticas. La iluminación en la fotografía jugó un papel fundamental para la recopilación de datos. En el caso de los artefactos líticos, pulidos, las características y variabilidades de la piedra son difíciles de distinguir a simple vista. Por eso, para obtener imágenes de superior calidad, se colocó el artefacto de tam manera que se minimizara los efectos del reflejo para que la luz y la cámara pudiera distinguir las huellas de uso sin perder el foco en la zona. Este es un factor que es difícil de conseguir al fotografiar filos biselados, ya que la profundidad de campo entre los puntos de enfoque crea una diferencia de enfoque considerable.

\section{CONSERVACIÓN A TRAVÉS DE LA IMAGEN}

Como con muchos avances científicos, la fotografía fue el resultado de la llegada de descubrimientos en la aplicación de principios de física y química desde en varios países (Dorrell, 1989, p. 1). En el pasado, el uso de fotos para documentación era difícil y limitado, especialmente las fotos en color, debido al costo de impresión (Sutton \& Arkush, 2006, p. 25). Factores como el clima y la alteración termal deterioran la apariencia física de los materiales líticos a través del tiempo (Espenshade, 2014, p. 8). La imagen, no solamente la fotografía, es hoy un fenómeno complejo que sirve de herramienta perfecta para los arqueólogos y estudiosos disponer de una imagen fidedigna de la realidad, es reproducible y más económico que otros métodos. La fotografía se aplicó desde momentos muy tempranos a la arqueología y la reproducción de los nuevos objetos que se estaban descubriendo (González, 2001, p. 164). La documentación fotográfica para archivo crea un estudio del material para su posterior análisis y comprensión, creando un documento irreempla- 
zable como un medio de preservar lo que la excavación hacía desaparecer. En los países tropicales, se toman medidas preventivas en el momento de la construcción de los edificios destinados a conservar bienes culturales. Cuando las condiciones en un depósito arqueológico son desfavorables, la atmósfera puede ser una fuente peligrosa de contaminación y destrucción de materiales. Dada la gran variedad de artefactos y objetos de valor artístico y cultural dentro de la Colección Junghanns, la amplia gama de agentes destructores del clima tropical es un problema complejo y difícil que se plantea ante la preservación de dichos objetos. El dibujo y la fotografía como método de registro responde a los estándares tanto artísticos como técnicos, permitiendo así que una misma pieza pueda ser conocida, estudiada y comparada por profesionales que estén distantes del depósito que alberga la pieza, y sin la necesidad de la pieza trasladarse. También forman una parte intrínseca del proceso técnico y su evolución. El registro fotográfico es mucho más rápido y reproduce la realidad tal cual es. El registro mecánico de la fotografía digital se reproduce instantáneamente, sin intervención alguna por parte del fotógrafo. El dibujo es mucho más lento, basándose en la interpretación del artista y su posible estilo técnico.

\section{TIPOS DE HERRAMIENTAS}

Este análisis de 146 artefactos líticos identificó la utilidad de varios rasgos morfológicos. Durante el proceso, se determinó que las mismas pudieron haber sido utilizadas para varios trabajos agrícolas y/o trabajos en madera. Tampoco se descarta que, a través del reciclaje, algunas de estas pudieron funcionar como percutores $\mathrm{y} / \mathrm{o}$ herramientas utilizadas para otros trabajos en piedra.

\section{Hachas Pulimentadas}

Son un artefacto de piedra pulida con cuello, y fue parte importante del conjunto tecnológico de los primeros grupos de agricultores-alfareros en las selvas occidentales. Se emplea el término simple de "hacha" para designar que, por lo general, un hacha es un artefacto pulido; pero que también pudo haber sido confeccionado a través de percusión. Frecuentemente las hachas también son usadas como cuñas, especialmente cuando son delgadas, ya que desde el punto de vista práctico no vale la pena fabricar cuñas especiales (Vega, 1975, p. 226). Un elemento final en la funcionalidad de las hachas es el mango, un instrumento alargado hecho en materiales resistentes y flexibles de madera, hueso o asta (con función de astil) que se colocaba perpendicularmente a la lámina del hacha pulida, proporcionando mayor eficacia en el movimiento mecánico de percusión lineal lanzada (Darriba, 2013, p. 5). (ver figura 04) 


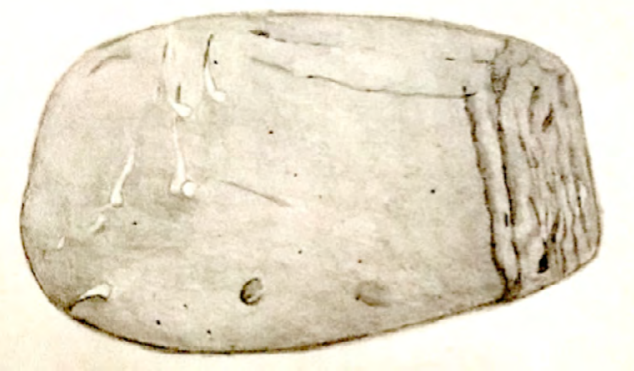

Figura 04. Hacha pulimentada

\section{Hachas Petaloides}

La denominación petaloide proviene de la silueta de plano del hacha, recordando los pétalos de flor, siendo el término más propio, aunque menos usado es el de amigdaloides, por su forma tridimensional de almendra (Herrera, 1964, p. 45). Se denominan hachas petaloides a ciertos arqueolitos de tipo común, cuya morfología es generalmente husiforme, pero con un extremo ampliamente modificado en una porción ancha de borde curvo y filoso que posee un extremo o vértice más o menos agudo, cónico y otro cortante, usualmente parabólico, en semi-círculo perfecto o en arco rebajado regular (Herrera, 1964, p. 15). Se denominan las hachas petaloide a aquellos arqueolitos en el cual su morfología es husiforme, con un extremo modificado en la porción ancha del borde curvo y filoso que posee un extremo agudo, cónico y otro extremo cortante, usualmente parabólico, en semi-circulo perfecto o en arco rebajado regular (Herrera, 1964, p. 15)

Las hachas petaloides no tienen ranura u otras modificaciones para el montaje, pero se cree que fue insertada en un mango de madera. Hechas en diferentes tipos de piedra (generalmente de roca ígnea o metamórfica), se han encontrado hachas de piedras más blandas, como caliza y/o piedra arenisca, entre otras. La piedra utilizada para éste tipo de instrumento fue trabajada a través de un proceso de picoteo para darle forma al artefacto, y luego completado por el alisamiento de la superficie con una piedra abrasiva adecuada. Las hachas petaloides también varían en forma y son generalmente en forma de cuña en un extremo y su cuerpo principal del artefacto se extiende de triangular a oval o en forma rectangular. La sección del bisel tiende a ser redondeado, pero también puede ser bastante puntiagudo o incluso rectangular y con la punta roma. Sus secciones transversales también varían de una sección, y son de en forma delgada en lugar de gruesa y también redonda en la misma sección. Estas diferencias en formas de las hachas petaloides reflejan en parte diferentes grupos o diferentes localidades, como las que se encuentran en algunos 
conjuntos arqueológicos que son bastante uniformes en estilo. El estilo de hacha en forma almendrada se encuentra entre los pueblos indígenas del gran arco continental del Caribe, en civilizaciones de distintos grados anteriores al Descubrimiento, desde las Guyanas hasta Florida, contando con la América Central, pero en su mayor abundancia y con las hechuras más perfectas, que constituyen el instrumento lítico típico del gran conglomerado social antillano, de principal origen Arawako sudamericano (Herrera, 1964, p. 15). Las variaciones de hachas encontradas son:

- Con forma de pétalos (petaloide): Estas no poseen una indicación de ranura o ampliación para el enmangamiento.

- Con borde de corte sencillo y con muescas en el borde opuesto: Son generalmente planas o ligeramente curveadas.

- Con cabeza agrandada: Tienen el diámetro mayor que el espesor de la hoja.

- Con ranuras para enmangamiento y punta roma. (ver figura 05)

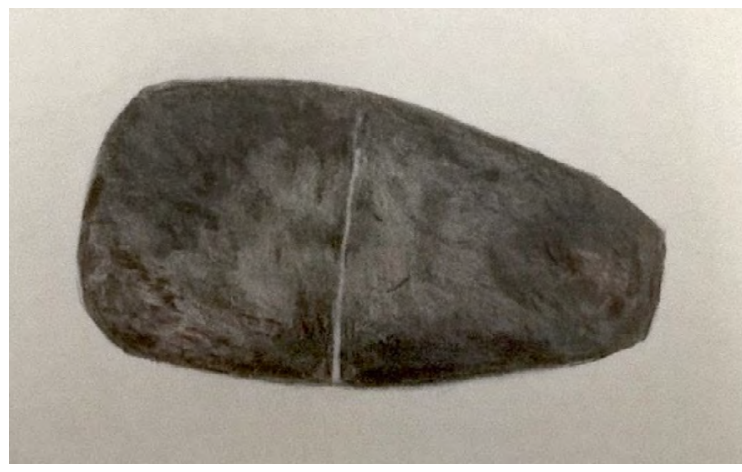

Figura 05. Hacha petaloide

\section{Hachas de Cuello}

El poliformo destral (hacha de cuello) es de afiliación dudosa, a pesar de su abundante hermandad con el hacha petaloide en la Isla de Santo Domingo, pero intrigantemente escaso en Cuba, y ausente en Puerto Rico, para hallarse en gran número de las Antillas Menores, desde Guadalupe a Granada donde parecen haberse originado en un período muy anterior a los Caribes (Herrera, 1964, p. 13). Algunos autores como Fewkes, Sven Lovén y Huckerby, consideran a esas hachas de cuello como pre-caribes, de la cultura Ignerí (primera ola migratoria de los ceramistas y agricultores sudamericanos) (Herrera,1964, p. 14). La realidad es que, pese al esfuerzo de todos los arqueólogos, que desde los fines del pasado siglo hasta el momento actual se han ocupado de las Antillas, la incógnita de las hachas de cuello sigue en pie, como una de las tantas lagunas en el estudio arqueológico del Archipiélago, sin tenerse la absoluta certeza del grupo cultural con que llegan a la región del Caribe, ni el período 
en que aquí se desenvuelven en su multitud de formas (Herrera, 1964, p. 15).

El hacha de cuello es de hecho el arma más eficaz de los indio-antillanos, y fue sin duda por su imponente aspecto guerrero, unido a la abundancia en las Antillas Menores, legendarias de tierras Caribes, el que fueran asignadas por algunos arqueólogos (Herrera, 1964, p. 31). Al contrario del hacha

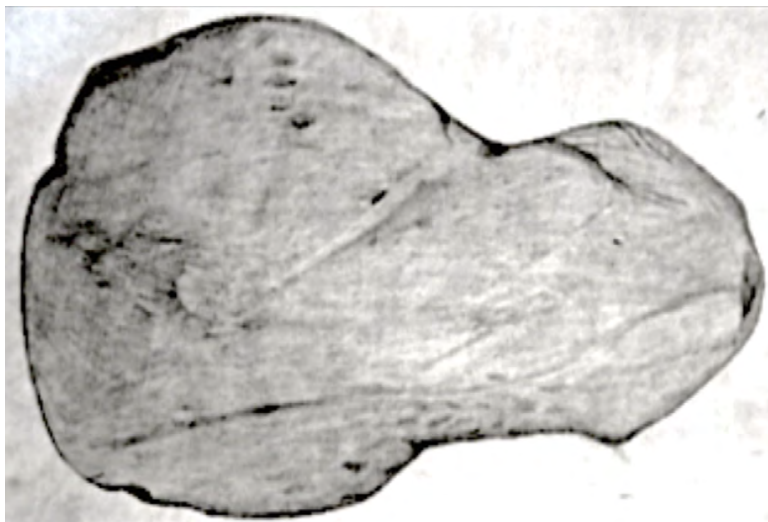

Figura 06. Hacha de cuello petaloide, de inmutable diseño conservado por el indígena aún en sus variantes, el hacha de cuello es de gran extensión proporcional del filo, y su falta de brillado es aún en aquellas cuyo material lo hubiera permitido fácilmente (Herrera, 1964, p. 32) (ver figura 06).

\section{Hachas Destrales}

Considerada como una herramienta pequeña o un arma formada por una piedra aplanada de figura elíptica, ovoide o puntiaguda, tallada por ambas caras y que se maneja por lo general con una sola mano con un mango de madera. Su extremo es filoso y de cierta extensión e imparte a la pieza su carácter de hacha, y aunque se conserven otras similitudes morfológicas, sólo podrá ser considerada como un artefacto destralifor-

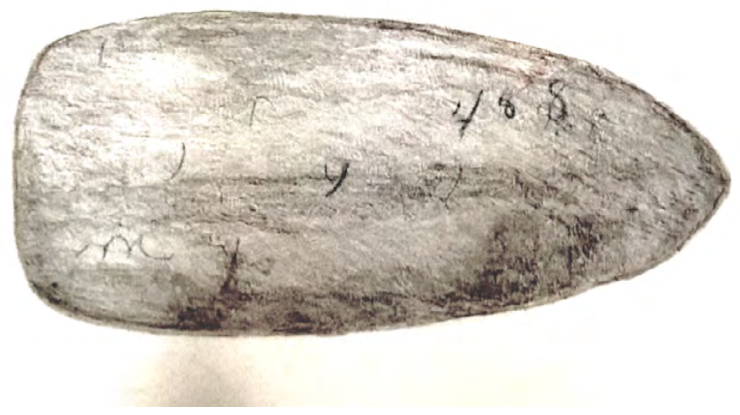

Figura 07. Hacha destral me (nódulo, percutor, pulidor, instrumento o destraliforme). Es decir, con la forma de un destral o hacha de mano, sin construir un propio instrumento tajante (Herrera, 1964:45) (ver figura 07).

\section{Hachas Perforadas}

Éstas hachas poseen una forma general triangular o subtriangular, con una perforación en su extremo proximal no apta para enmangues. Sus filos son ensanchados, con tendencias semicirculares y con una sección transversal aplanada elaborada cuidadosamente en materiales poco frecuentes (ver figura 08). 


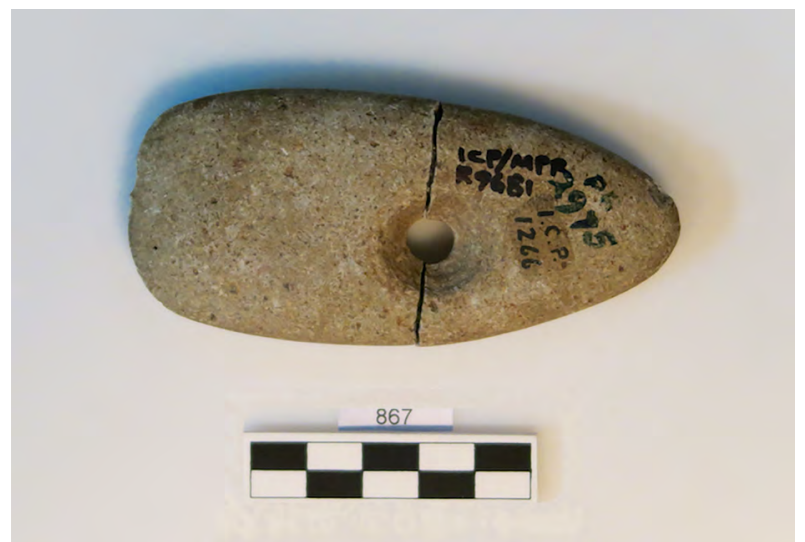

Figura 08.
Clase tecnológica: Hacha petaloide con perforación bicónica central Morfología: Extremo Apuntado

Acabado: Bruñido

Peso: $113.2 \mathrm{~g}$

Largo: $98.21 \mathrm{~cm}$

Ancho: $45.16 \mathrm{~cm}$

Grosor: $16.47 \mathrm{~cm}$

Filo vista dorsal: Redondeado

Talón: En ángulo

Corte transversal: Semi-elíptica

Bisel: Simétrico convexo

Número de catálogo: 867

Número de colección: ICP 1266 PR 2975 PR MPR-R-96-81

\section{Azuela de Piedra}

La azuela posee una morfología similar a la del hacha, pero se diferencia en que presenta un filo asimétrico, mientras que el del hacha es siempre simétrico, o ligeramente asimétrico. Las azuelas son artefactos que poseen un corte por percusión directa, que presenta atributos morfológicos constantes parecidos al de la hoja simple enmangada, en el bisel asimétrico convexo, el filo curvo observado en la vista frontal y en el arco rebajado en vista dorsal. (Sosa, 1976, p.224). La azuela es una herramienta para trabajar la madera y es un tipo de hacha de mango corto con la hoja dispuesta perpendicular a dicho mango. Las azuelas pulimentadas se usaron normalmente con un mango para mayor efectividad. El enmangue de la azuela en el astil sigue el eje del mismo, a diferencia del hacha. Se entiende que se utilizaba para desbastar, alisar, ahuecar, amoldar formas torneadas y esculpir tallas de madera (ver figura 09). 


\section{Buril}

Los buriles son arqueolitos que guardan una sensible analogía con las hachas petaloides, tanto en su fino acabado como en su disposición cortante, forma, manualidad, longitud, promedio, y el escogido e idéntico material en que están labrados. (Herrera, 1964, p. 54) Como util prehistórico, es usualmente elaborado a partir de una lasca o lámina de piedra a través de la técnica de golpe de buril, técnica especial usada para retocar la piedra pulimentada. Esta técnica de construcción se basa en la creación de facetas longitudinales u oblicuas al eje longitudinal de la pieza. El buril es una herramienta fabricada en preformas, fundamentalmente laminares, y en el proceso de su elaboración, se extrae las lascas denominadas como "virutas de buril", dejando un lascado negativo perpendicular en el plano de aplastamiento del soporte. Esta herramienta se utilizaba en la fabricación de utensilios de hueso o de asta, como por ejemplo las azagayas o arpones. Era usada para la elaboración de grabados e incisiones de roca, hueso y asta, además de para la confección de objetos de arte. Estas facetas presentan ángulos filosos similares a los buriles metálicos.

La idea mantenida hasta ahora por arqueólogos es de separar los buriles de las hachas petaloides como dos instrumentos esencialmente distintos (Herrera, 1964, p. 54). El material de los buriles, así como su perfecta simetría bilateral, alto pulimento y conservación de los filos en la mayoría de los casos, inducen a pensar que, como las hachas petaloides, no se tratan de instrumentos de trabajo, sino que hay en ellos una dedicación menos material, posiblemente votiva de amuleto, o propia de ciertos rituales que hasta ahora desconocemos, pero que en ningún modo pueden considerarse como vulgares herramientas domésticas (Herrera, 1964, p. 53). Los buriles son artefactos que se han encontrado en estratos del Paleolítico medio, pero han sido más abundantes en los estratos del Paleolítico superior. Esto coincide con la gran eclosión de los objetos de hueso y asta. Los buriles son usualmente alargados, de manera husiforme. Son particularmente agudos y filosos, pero también pueden encontrarse de forma cilíndrica y aplanada, con una sección elíptica (ver figura 10).

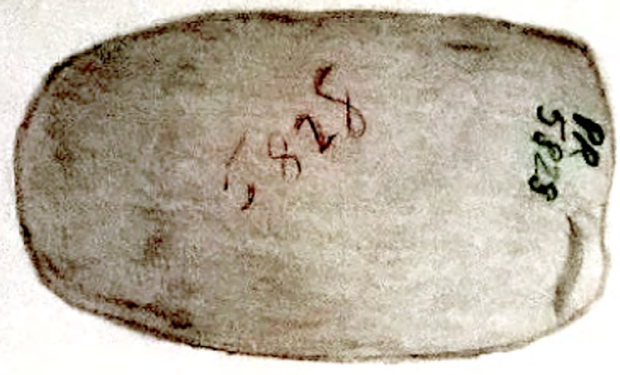

Figura 10. Buril 


\section{Cuña}

Son herramientas de corte por percusión indirecta, elaboradas en lascas aplanadas o ligeramente gruesas, así como también en fragmentos de núcleos pequeños. Presentan en uno o en ambos extremos de las superficies dorsal y ventral una serie de cicatrices superpuestas que conforman las

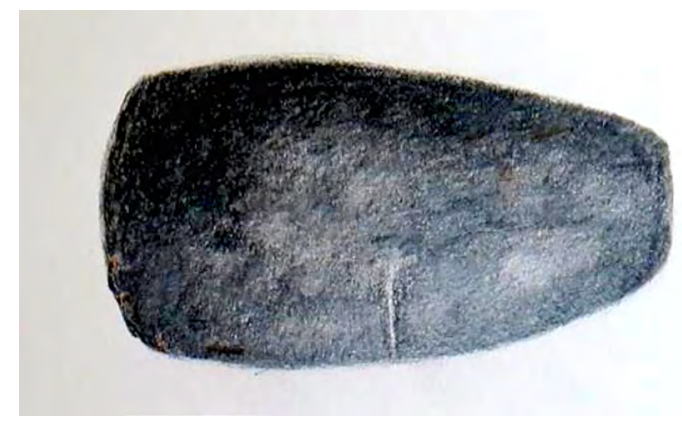

Figura 11. Cuña llamadas "crestas" que son producto del trabajo lítico. Estas piezas vistas en perfil tienen el extremo de trabajo cuneiforme, con hoja simple sin enmangar, sección transversal circular, filo recto en vista frontal, bisel simétrico convexo y talón totalmente romo preparado para recibir el golpe del percutor (Vega, 1975, p. 230). Frecuentemente, las hachas también son usadas como cuñas, especialmente cuando se requiere que éstas sean delgadas. Presentan características morfológicas muy homogéneas por la función a que están destinadas y todas tienen huellas claras de golpeo en el talón (ver figura 11)

\section{Gubia}

La gubia es un útil de desarrollo longitudinal, cuya morfología general muestra una silueta fusiforme de aristas paralelas curvas, destacando la zona activa, con un filo convexo simétrico y ahuecado que la clasificaría como el tipo de gubia. (Darriba, 2013, p. 2) La gubia tiene un filo estrecho, con una cara convexa y cóncava a la opuesta. Estos instrumentos poseen una forma alargada, y presenta un contorno fusiforme. Son una piedra pulida de pequeño tamaño, parecidos a los cinceles, pero con un bisel muy agudo y curveado. Posee un hendidura de forma conocida y servían para agujerear los astiles y las mortajas en donde iban colocadas las hachas de piedra usadas para talar y cavar los terrenos. La gubia se caracteriza por sus cualidades como artefacto multipropósito, y fue usada como una azuela para elaborar embarcaciones y viviendas, para desmontar terrenos con fines agrícolas y para labrar la tierra en épocas de siembra y cosecha. También pudieron ser usadas como azada y coa para excavar y como útil para el aborigen en su búsqueda de alimentos. Las gubias son instrumentos de corte por presión que presentan características morfológicas constantes, tales como los de una hoja simple. Poseen un arco rebajado en su vista dorsal y curvo en la vista frontal. Tiene un bisel lateral, con lados convexos convergentes y su talon es recto, con una zona de trabajo definida como el de las secciones transversales. (Vega, 1975, p.230). Según su forma, se puede inferir de que es fue utilizado como un instrumento de carpintería para ahondar y alisar la madera (ver figura 12) 


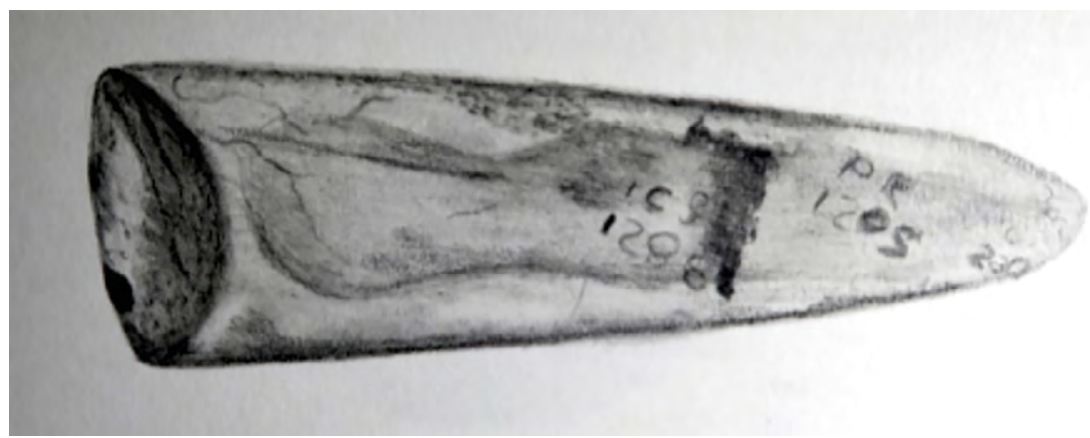

Figura 12. Gubia

\section{Cincel}

La palabra "cincel" normalmente se refiere a una herramienta con un borde plano afilado en un extremo, poseyendo una función más similar a la del buril (Usai, 2005:297) y se reconoce como una herramienta de piedra utilizada en la producción de un petroglifo. El cincel prehistórico fue diseñado a través de la técnica del picoteo, en el cual se reduce la piedra mediante la remoción de la superficie de la masa pétrea.

Los rasgos morfológicos relativamente más variables son: lados convexos divergentes y bisel simétrico convexo. Los cinceles se emplean para obtener cortes finos en piedra o madera y se utilizan generalmente para obras de escultura. (Sosa, 1976, p. 228) El cincel destraliforme surge del aprovechamiento de la pala del hacha petaloide, que por accidente perdió su punta, apareciendo como 'medias hachas', cortas y de cotillo grueso como un muñón, disforme casi siempre por las huellas de una prolongada percusión sobre él (Herrera, 1964, p. 52) (ver figura 13).

\section{4}

Figura 13. Cincel 


\section{Martillo}

El martillo como herramienta de percusión es utilizado para golpear una pieza, ya sea directa o indirectamente, con el fin de causar un desplazamiento o algún tipo de deformación en la pieza. Su forma básica consiste en un mango con una cabeza pesada en uno de sus extremos. El uso más común es para incrustar, calzar partes o romper una pieza (ver figura 14).

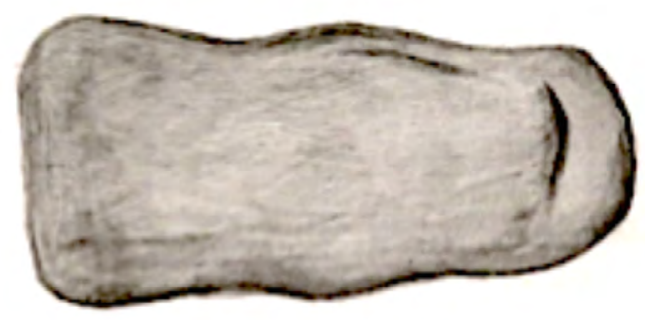

Figura 14. Martillo

\section{Enmangue}

El enmangado es creado para amarrar el talón de la piedra al mango y posee una variante que permite aplicar el golpe de manera transversal al plano de percusión. Las estrías dejadas por el uso de la herramienta son paralelas al eje longitudinal de la hoja de la piedra. Por lo tanto, son más marcadas en la cara ventral por ser el area en que el material es trabajado. (Vega, 1975, p. 226) El enmangado de útiles se realiza fijando la hoja al mango por medio de cuerdas hechas de fibras vegetales, cordones de pieles, tripas y tendones de animales y por inserción del hacha en un mango de madera.

\section{RESULTADOS}

Los estudios tecnológicos en la arqueología son de suma importancia, teniendo en cuenta de que los utensilios que pertenecen a un momento de la historia introducen nuevas técnicas de fabricación de artefactos utilitarios debido a las diferentes actividades relacionadas a la subsistencia. Estas actividades aparentan ser vinculadas a trabajos relacionados a la tala de árboles y el desbaste de troncos, también como a trabajos de la tierra. La mayoría de los estudios funcionales describen explicaciones simplistas, y usualmente se les asignan los usos para la tala de árboles y las azuelas para los trabajos de carpintería. No obstante, la nomenclatura en la tipología mantiene criterios descriptivos dependiendo de su morfología y la variabilidad de sus usos. La tipología estudiada para éste análisis categoriza criterios que están directamente relacionados con la funcionalidad usando los siguientes grupos morfológicos: 
- Grupo I: Artefactos utilitarios con extremos cortantes:

- Tipo I: Artefactos utilitarios con extremo cortante y bisel asimétrico

- Tipo II: Artefactos utilitarios con extremo cortante y bisel simétrico

- Tipo III: Artefactos utilitarios con extremo cortante y Bisel rectilíneo asimétrico

- Grupo II: Artefactos utilitarios con extremo apuntado

- Grupo III: Artefactos utilitarios de extremo redondeado

El material analizado también demostró que la mayoría de los artefactos (un 39\% del material) posee una morfología con extremo cortante, dando espacio al estudio y exploración del uso de estas herramientas. A nivel de la morfología del estudio, se demostró que predominaron artefactos con arco redondeado. El proceso de recopilación de información referente a los materiales crudos pudiese facilitar comparaciones en un futuro dentro de los hallazgos arqueológicos en la región de Las Antillas y el Circum-Caribe. Durante en el proceso del análisis, en el registro se pudo evidenciar las huellas de enmangue, considerando que la mayoría de la evidencia encontrada en las herramientas estudiadas eran insertadas dentro del enmangue.

El enmangue pudo haber sido directo, es decir la pieza va encajada directamente en el mango, o indirecto con la utilización de una pieza intermedia. La forma del mango está íntimamente relacionada con la función a la que es destinada la herramienta. La pieza va encajada en el mango, o en ocasiones está indirectamente encajado a una pieza intermedia. La forma del enmangue es directamente relacionada con el funcionamiento al que está destinado la herramienta. La eficacia del manejo del artefacto depende de las medidas en que el útil, el tipo de roca, la funcionalidad de las dimensiones y el peso que tengan. Los individuos que manejaban éstos artefactos pulimentados poseían un conocimiento muy particular para poder saber qué tipo de materia prima usar y cómo transformar las diferentes herramientas de trabajo. Se puede argumentar que la ciencia arqueológica contemporánea en Puerto Rico es el resultado de más de 150 años de actividad. (Rodríguez, 2013, p. 137) Sus orígenes se remontan a la primera mitad del Siglo XIX cuando se realizaban actividades de anticuarismo y coleccionismo de manera aislada, principalmente por profesionales y personas de clases acomodadas. (Rodríguez, 2013, p. 137)

En el pasado, las colecciones y materiales arqueológicos recopilados no se utilizaban para ningún propósito científico, sino más bien, como "curiosidades" y piezas de colección. (Rodríguez, 2013, p. 137) El hecho de que Puerto Rico sirvió como ubicación central donde la cronología cultural de Rouse del Caribe insular fue erigida hace evidente que esta revisión de la arqueología e historia de la isla es larga y que también podría tener implicaciones para el resto de las regiones de las Antillas. (Rodríguez, 2010, p. 8) A través del estudio detallado de las materias primas utilizadas para la producción de herramientas líticas y sus tradiciones tecnológicas objetiva- 
das ante la fabricación artefactos de piedra de varios sitios de la isla, una diferente perspectiva es renovada en relación a las formas en que los pueblos precoloniales de Puerto Rico pudieron haber intercalado sus identidades y cómo estos compromisos articularon el paisaje cultural de la isla a través del tiempo. (Rodríguez, 2010, p. 8) La colección contiene alrededor de 12,400 objetos, analizando sólo el 12.5\% de los artefactos. En un futuro, un amplio análisis geo-arqueológico de las piezas aportaría a estudios similares para el esclarecimiento del problema de identificación de procedencia en artefactos. El obtener un mayor conocimiento sobre las sociedades del pasado, especialmente de las prehistóricas, sólo es posible a través del estudio de los restos de aquellos yacimientos. Asimismo, conocer los procesos de la evolución en la relación ser humano-medioambiente puede aportar claves críticas para el futuro a la hora de definir y caracterizar áreas, tipos de terreno y/o materias primas.

\section{ANEXO}

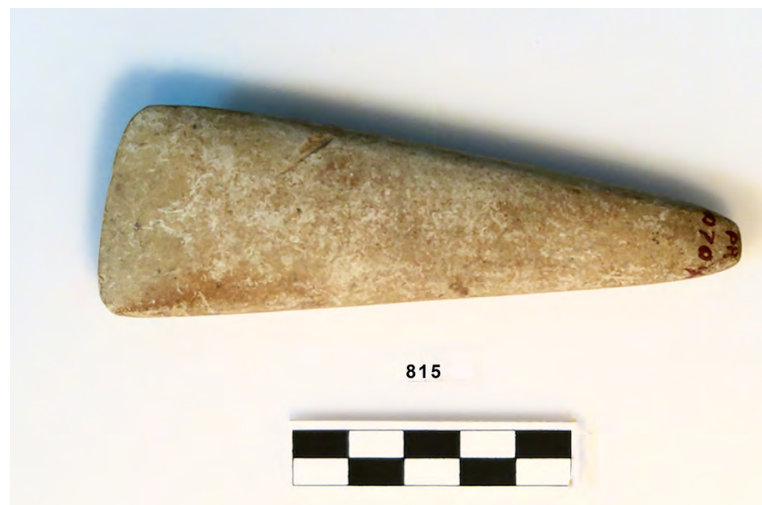

Figura 15

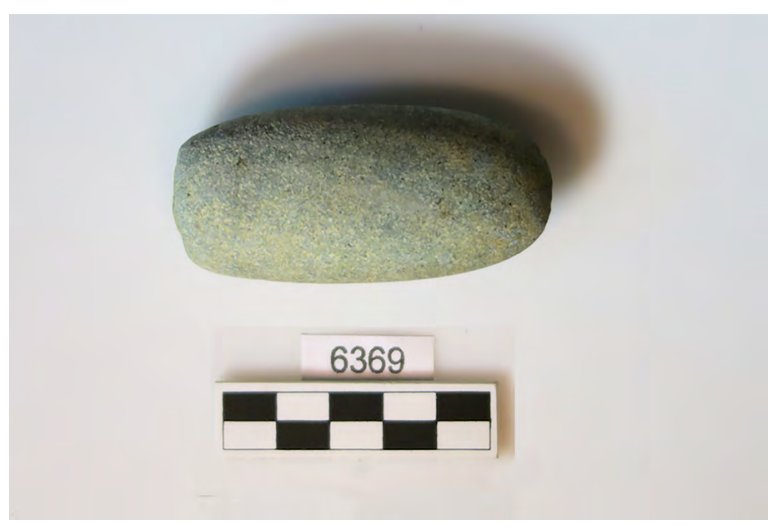

Figura 16
Clase tecnológica: Azuela de Piedra Morfología: Extremo cortante Acabado: Bruñido

Peso: $107.9 \mathrm{~g}$

Largo: $114.38 \mathrm{~cm}$

Ancho: $36.68 \mathrm{~cm}$

Grosor: $19.82 \mathrm{~cm}$

Filo vista dorsal: Rectilíneo

Talón: En ángulo

Corte transversal: Elíptica 2

Bisel: Simétrico

Número de catálogo: 815

Número de colección: PR10704

Clase tecnológica: Cincel

Morfología: Extremo cortante

Acabado: Pulido

Peso: $74.27 \mathrm{~g}$

Largo: $70.45 \mathrm{~mm}$

Ancho: $21.75 \mathrm{~mm}$

Grosor: $30.41 \mathrm{~mm}$

Filo vista dorsal: Rectilíneo

Talón: En ángulo

Corte transversal: Elíptica 1

Bisel: Rectilíneo asimétrico

Número de catálogo: 1022

Número de colección: ICP/MPR-R-96-70

PR 133454 


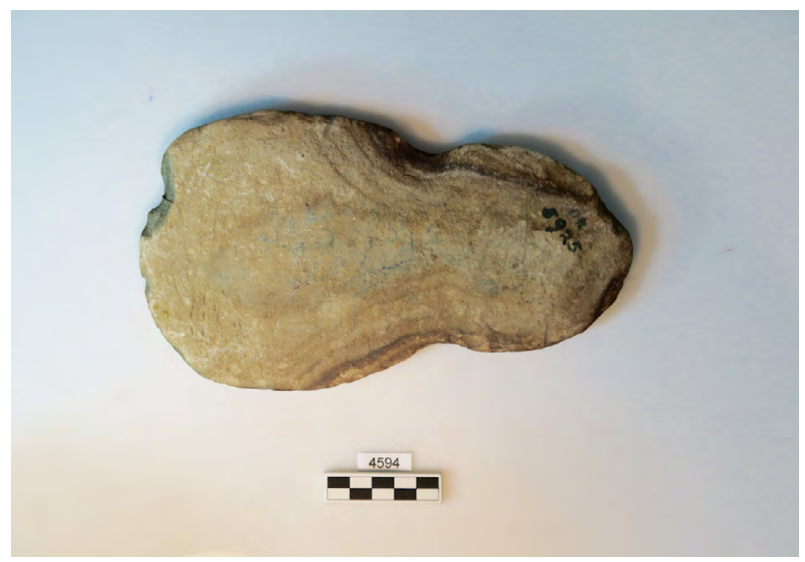

Figura 17

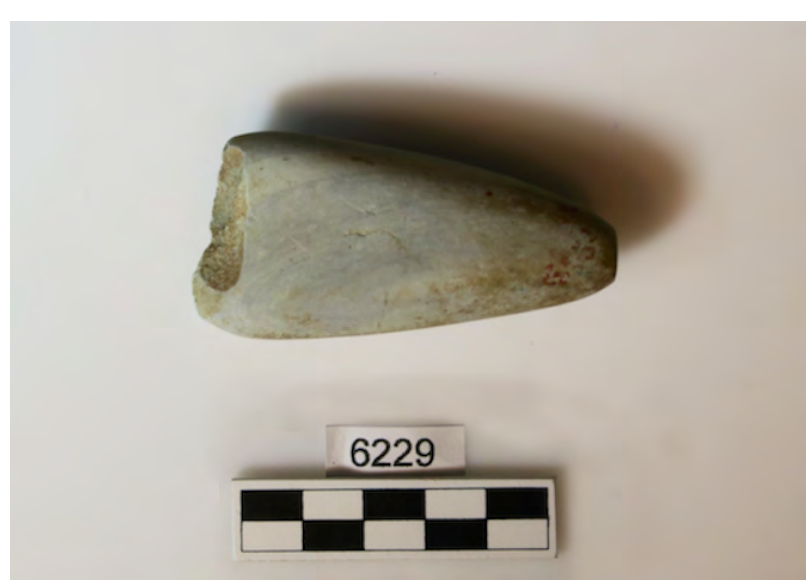

Figura 18

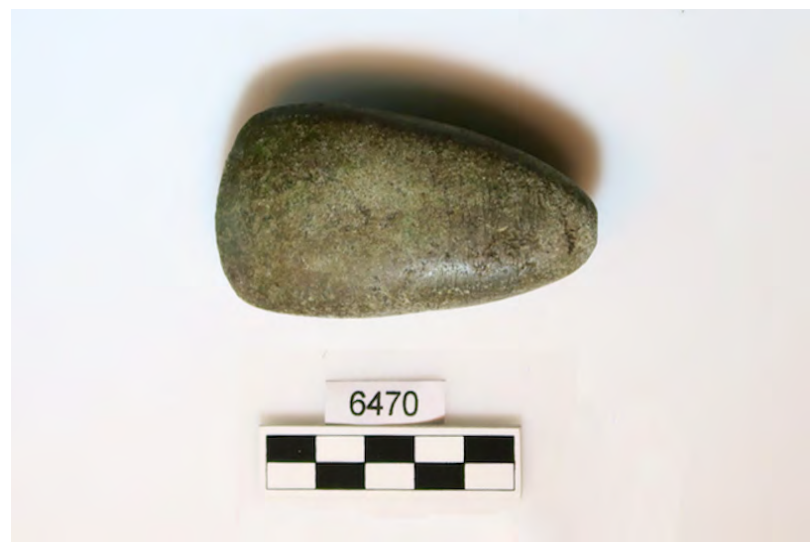

Figura 19
Clase tecnológica: Hacha de cuello Morfología: Extremo cortante Acabado: Pulido

Peso: $733.1 \mathrm{~g}$

Largo: $232.23 \mathrm{~mm}$

Ancho: $131.46 \mathrm{~mm}$

Grosor: $16.48 \mathrm{~mm}$

Filo vista dorsal: Redondeado

Talón: Redondeado

Corte transversal: Elíptica 2

Bisel: Rectilíneo asimétrico

Número de catálogo: 4594

Número de colección: PR 5925

Clase tecnológica: Cuña

Morfología: Extremo apuntado

Acabado: Bruñido

Peso: $64 \mathrm{~g}$

Largo: $68.77 \mathrm{~mm}$

Ancho: $31.83 \mathrm{~mm}$

Grosor: $19.53 \mathrm{~mm}$

Filo de vista dorsal: Fragmentado

Talón: En ángulo

Corte transversal: Elíptica 1

Bisel: Fragmentado

Número de catálogo: 6229

Número de colección: PR 1073

Clase tecnológica: Hacha

Morfología: Extremo apuntado

Acabado: Bruñido

Peso: $64 \mathrm{~g}$

Largo: $104.5 \mathrm{~mm}$

Ancho: $76.78 \mathrm{~mm}$

Grosor: $39.29 \mathrm{~mm}$

Filo de vista dorsal: Redondeado

Talón: Redondeado

Corte transversal: Elíptica 1

Bisel: Simétrico

Número de catálogo: 6470

Número de colección: PR 8318 


\section{REFERENCIAS BIBLIOGRÁFICAS}

Alegría, R. (1981). El Uso de la Terminología Etno-histórica para designar las culturas aborígenes de las Antillas, Cuadernos Pre-hispánicos Valladolid, Seminario de Historia de América, Universidad de Valladolid.

Alegría, R. (1981). El uso de la incrustación en la escultura de los indios antillanos. San Juan: Centro de Estudios Avanzados de Puerto Rico y el Caribe en colaboración con el Museo del Hombre Dominicano, Santo Domingo.

Alegría, R \& Rouse, I. (1990). Excavations at María de la Cruz Cave and Hacienda Grande Village Site, Loiza, Puerto Rico, Department of Anthropology and the Peabody Museum, Yale University Publications in Anthropology.

Balme, J. \& Paterson, A .(2006). Archaeology in Practice, A Student Guide to Archaeological Analyses, Blackwell Publishing, Malden, MA.

Darriba Barba, X (2013). Piezas Líticas Pulidas, Museo Arqueológico Provincial de Ourense, Pieza del Mes Junio 2013, Recuperado de: http://www.musarqourense.xunta.es/wp-content/files_mf/piliÚtileslíticospuÍdos_7_rev_araceli_6_xunta_4_esp.pdf

Dorrell, P. G. (1989). Photography in Archaeology and Conservation, Second Edition, Institute of Archaeology, University College London, Cambridge University Press.

Espenshade, C.T (2014). The Cultural Landscape of Jácana: Archaeological Investigations of Site PO-29, Municipio de Ponce, Volume II, Part 7: The Lithic Artefacts of Jácana, Final Report, US Army Corps of Engineers, Jacksonville District, Florida, US.

Fitzpatrick S. (2015). The Pre-Columbian Caribbean: Colonization, Population Dispersal, and Island Adaptations, W. S. Maney \& Son Ltd and the Center for the Study of the First Americans Paleo America VOL. 1 №. 4 University of Oregon, Eugene, OR.

Frick, J.A., \& Herkert K. (2014). Lithic Technology and Logic of Technicity, 1 Universität Tübingen Institut für Ur- und Frühgeschichte und Archäologie des Mittelalters Abteilung Ältere Urgeschichte und Quartärökologie, Schloss Hohentübingen, Tübingen, Germany.

González Reyero, S. (2001). Los usos de la fotografía en favor de la arqueología como ciencia moderna. Francia 1850-1914, CuPAUAM 27, pp. 163-182, Recuperado de: https://www.uam.es/otros/cupauam/pdf/Cupauam27/2709.pdf

Herrera Fritot, R. (1938). Revisión de las hachas de ceremonia de la Cultura Taína; presentación de nuevos ejemplares del Museo Montané, Universidad de La Habana, Cuba.

Herrera Fritot, R. (1964). Estudio de las hachas antillanas; Creación de índices axiales para las hachas petaloides, Departamento de Antropología, Comisión Nacional de la Academia de Ciencias, La Habana, Cuba. 
Peytrequín, J. (2011). Artefactos líticos lasqueados, picados y pulidos. Descripción, clasificación y funcionalidad. Material de apoyo didáctico. Arqueología de la Escuela de Antropología, Universidad de Costa Rica. San José, Costa Rica.

Ramos, R. y Pagán Jiménez, J. (2006). Interacciones multivectoriales en el circum-Caribe precolonial. Un vistazo desde Las Antillas. Caribbean Studies, 34.

Ramos, R. y Pagán Jiménez, J. (2008). Sobre arqueología de liberación en una 'colonia postcolonial': el caso de Puerto Rico. Revista de Ciencias Sociales, 19, p. 8-41.

Rodríguez López, J. (2013). Apuntes para la Historia de la Arqueología de Puerto Rico, Taller de Ediciones Puerto, San Juan, Puerto Rico.

Rodríguez Ramos, R. (2010). Rethinking Puertorrican Precolonial History, Tuscaloosa University of Alabama Press

Rodríguez Ramos, R.(2008). From the Guanahatabey to the Archaic of Puerto Rico, The Nonevident Evidence Universidad de Puerto Rico in Utuado, Ethnohistory 55(3), 393-410. American Society for Ethnohistory.

Rodríguez Ramos, R. (2007). Puerto Rican Precolonial History Etched in Stone. Doctoral Dissertation, Archaeology, University of Florida, Gainesville.

Rodríguez Ramos, R. (2006). Lithic Productions Dynamics at Paseo del Indio Site, Puerto Rico, Fase III , Vega Baja, Río Abajo, Consejo de Arqueología Terrestre, Instituto de Cultura, San Juan, Puerto Rico.

Rodríguez Ramos, R. (2005). El Caribe en el Contexto del Circun-Caribe: Medio Siglo más Tarde. Paper presented at the $21^{\text {st }}$ International Congress for Caribbean Archaeology, Trinidad.

Rodríguez Ramos, R. (2002). Dinámicas de Intercambio en el Puerto Rico Pre-hispánico, Trabajos de Investigación Arqueológica, IV Encuentro de Investigadores, Instituto de Cultura Puertorriqueña, Publicación Ocasional de la División de la Arqueología del ICP, San Juan, Puerto Rico.

Rodríguez Ramos, R. (2001). Lithic reduction trajectories at La Hueca and Punta Candelero sites, Puerto Rico: A preliminary report. Proceedings of the Eighteen ${ }^{\text {th }}$ International Congress for Caribbean Archaeology (1), pp. 251-261.

Rodríguez, López J. (2013). Apuntes para la Historia de la Arqueología de Puerto Rico, Antecedentes Históricos, Segunda Mitad del Siglo XIX. Ediciones Puerto Rico.

Rouse, I. (1992). The Tainos: Rise and Decline of the People Who Greeted Columbus. Yale University Press.

Rouse, I. (1986). Migration in Prehistory, Inferring Population Movement, Yale University Press, New Haven and London 
Rouse, I. (1964). The Bailey Collection of Stone Artifacts from Puerto Rico in Essays in Pre-Colombian Art and Archaeology, Samuel Lothrop, Harvard University Press, Cambridge MA (pp. 343-355).

Rouse, I. (1952). Puerto Rican Prehistory, Scientific Survey of Puerto Rico and the Virgin Islands. Academy of Sciences. Vol. 18, New York.

Usai, D. (2005). Chisels or Perforators? The lithic Industry of Ras al-Hamra 5 (Muscat, Oman), Proceedings of the Seminar for Arabian Studies 35, Pp 293301, Recuperado del enlace: http://s3.amazonaws.com/academia.edu. documents/12279292/Usai_2005.pdf?AWSAccessKeyId=AKIAJ56TQJRTWSMTNPEA\&Expires $=1479744659 \&$ Signature $=A 4 P \% 2 B \% 2 B$ Ar0nQQ89x0LVviljduNU9c\%3D\&response-content-disposition=inline\%3B\%20filename\%3DChisels_or_perforators_The_lithic_indust.pdf

Knippenberg, S. (2006). Stone artefact production and exchange among the northern Lesser Antilles, Doctoral Thesis, Department of Caribbean Archaeology, Faculty of Archaeology, Leiden University

Pantel, Agamemnon G. (1988). Precolumbian Flaked Stone Assemblages in the West Indies, PhD Diss, University of Tennesee

Rodríguez Ramos, R., Hofman, C., Knippenberg, S. (2013). Enfoques transdisciplinarios en el estudio del pasado indígena del Caribe, Aproximaciones botánicas, líticas y metalúrgicas, Revista Instituto de Cultura Puertorriqueña, Año 12 (24), pp. 49-62

Veloz Maggiolo, M. (1979). Notas históricas sobre la Arqueología en las Antillas, Revista Española de Antropología Americana, Universidad Complutense de Madrid. http://revistas.ucm.es/index.php/REAA/article/view/REAA7979110123A

\section{SOBRE LA AUTORA}

\section{Nichole Bodin Cruz}

Maestría en Arqueología del Caribe del Centro de Estudios Avanzados de Puerto Rico y el Caribe. Bachillerato de Humanidades con concentración en Fotografía en Artes Plásticas de la Universidad de Puerto Rico, Recinto de Río Piedras. Grado Asociado en Comunicación Audiovisual de la Universidad de Puerto Rico, Recinto de Humacao. Ha publicado recientemente Opinion: Boriken's National Patrimony- A Diminishing Experience (2020), Río Cayrabón- It's time to fix a historic mistake. Borikén/ Puerto Rico (2011). Tiene como ejes de investigación, análisis y curación de colecciones arqueológicas, historia de Puerto Rico y preservación del patrimonio cultural. 